\title{
On the Hot Isostatic Pressing of Inconel 625 Structures built using Laser Powder Bed Fusion at Higher Layer Thickness
}

\section{Saurav Kumar Nayak}

Indore

\section{Arackal Narayanan Jinoop}

Indore

Christ Prakash Paul ( $\square$ paulcp@rrcat.gov.in )

Indore https://orcid.org/0000-0002-6233-4001

Vesangi Anil Kumar

Indore

Dineshraj Subburaj

Indore

Rashmi Singh

Indore

Kushvinder Singh Bindra

Indore

\section{Research Article}

Keywords: Laser Additive Manufacturing, Laser Powder Bed Fusion, Inconel 625, Hot Isostatic Pressing (HIPing), Characterization

Posted Date: November 30th, 2021

DOl: https://doi.org/10.21203/rs.3.rs-982054/v1

License: (a) (1) This work is licensed under a Creative Commons Attribution 4.0 International License. Read Full License

Version of Record: A version of this preprint was published at The International Journal of Advanced Manufacturing Technology on March 12th, 2022. See the published version at https://doi.org/10.1007/s00170-022-08960-4. 


\section{Abstract}

This paper reports the effect of Hot Isostatic Pressing (HIPing) on the porosity, microstructure and mechanical properties of Laser Powder Bed Fusion (LPBF) IN625 structures built at a higher layer thickness of $100 \mu \mathrm{m}$. It is observed that the process-induced pores/voids of volume fraction $\left(V_{f}\right) 0.43 \%$ in as-built IN625 structures are reduced significantly to 0.01\% after HIPing treatment. The microstructure is changed from fine columnar dendrites to coarse equiaxed dendrites. The microstructural analysis of as-built structures reveals the presence of cellular/ dendritic growth along with elemental segregation of $\mathrm{Nb}$, Si and $\mathrm{C}$ and precipitation of $\mathrm{Nb}$-rich carbides. Whereas, coarse recrystallized microstructure along with elemental segregation of $\mathrm{Si}$ and precipitation of $\mathrm{Nb}, \mathrm{Mo}$ and $\mathrm{Cr}$ rich carbides are observed in Hot Isostatic Pressed (HIPed) samples. HIPed structures exhibit lower tensile s trength, higher ductility, and lower anisotropy as compared to LPBF built structures. There is a reduction in the Vickers micro-hardness of IN625 samples after HIPing and the values are observed to be similar to their conventional counterparts. Further, an increase in the energy storage capacity of the material is observed after HIPing treatment through Automated Ball Indentation $\left(A B I^{\circledR}\right)$ studies. The study paves a way to develop 100\% dense, defect-free and isotropic engineering components using LPBF.

\section{Introduction}

Ni-based superalloys are the preferred choice of deployment in applications involving extreme duty conditions due to high mechanical strength, corrosion resistance, oxidation resistance and creep strength at elevated temperature (up to $~ 0.7$ times of the melting point) ${ }^{1,2}$. Inconel 625 (IN625) is one of the Nibased superalloys that finds wide applications in marine, aeronautics, chemical, aerospace, nuclear and petrochemical industries ${ }^{3}$. The alloy is solid solution strengthened with the addition of $\mathrm{Fe}$ and $\mathrm{Nb}$ into the $\mathrm{Ni}$ matrix and contains $\mathrm{Cr}$ and Mo for improving the corrosion resistance and high-temperature strength, respectively ${ }^{4-6}$. IN625 has excellent weldability with minimal cracking susceptibility and can be deployed for applications ranging from $0^{\circ} \mathrm{C}-1000^{\circ} \mathrm{C} 4,7,8$. However, one of the issues associated with the use of IN625 for many engineering applications is its difficulty in machining due to work-hardening during metal-cutting operation. Machining of IN625 block needs machining parameters in narrow window and selection of appropriate tools for circumventing the effect of work hardening and chatter; for reduction of residual stress build-up during machining; and for slowing down the wear of the tools and machines ${ }^{4}$. It necessitates adopting advanced manufacturing techniques, like - additive manufacturing for building near-net-shaped engineering components and avoiding excessive machining of IN625. There are many additive manufacturing techniques including laser directed energy deposition ${ }^{9,10}$, laser powder bed fusion

${ }^{11}$, electron beam-based additive manufacturing ${ }^{12}$, and wire-arc based additive manufacturing ${ }^{13}$ that can be deployed for these applications.

Laser powder bed fusion (LPBF) is one of the most commonly used additive manufacturing processes in industries to build complex-shaped engineering components due to the shape design freedom offered by the technology ${ }^{14,15}$. It starts with a 3D model sliced into several layers (2D sections) and material 
addition is carried out in a layer-by-layer sequence by selective fusion of the preplaced material using high power lasers ${ }^{15,16}$. LPBF provides the additional advantages of reduced tooling, geometric freedom, and mass customization over conventional manufacturing processes (i.e., machining or forming) ${ }^{17,18}$. However, LPBF suffers from inherent processing defects, such as - internal cracking, porosity, high residual stress, delamination, and high surface roughness, which can reduce the mechanical integrity of LPBF built parts ${ }^{19,20}$. These defects in LPBF can be resolved by adopting an appropriate manufacturing strategy including manoeuvring process parameters/ conditions and deploying suitable post-processing techniques ${ }^{21,22}$. As it is not viable to mitigate all the defects only by manoeuvring process parameters/ conditions, various post-processing techniques are deployed ${ }^{23}$.

HIPing is a post-processing technique that can reduce/ eliminate porosity and cracks to a greater extent 24. It involves subjecting the LPBF built part to an elevated temperature and high pressure simultaneously for pre-defined time facilitating the plastic deformation and the visco-plastic flow of the metal filling up the pores and the cracks present in the part ${ }^{25,26}$. Argon is generally used for pressurizing due to its inert nature. The pressure is applied from all directions equally, which makes the process "isostatic". The primary governing parameters of HIPing are inert atmosphere, temperature, pressure, and cycle time ${ }^{27}$. Depending on the temperature of the process, HIPing can also affect the microstructure and dislocation density in the as-built part, which in turn contributes to the change in its mechanical properties. The list of potential components that can use LPBF followed by HIPing are - gas turbine blades, satellite components, etc. requiring specific properties enabling their operation in hostile conditions, 1,4,28.

Many researchers are reporting the deployment of LPBF built IN625 parts with post-processing for various engineering applications. Hu et al. observed that the as-built samples at higher temperature showed reduced ductility due to inter-granular cracking as opposed to forged IN625. The inter-granular cracking at elevated temperature was attributed to the non-homogeneous grain distribution and carbide formation at the grain boundaries ${ }^{29}$. Li et al. found that no precipitation of carbides or other phases occurred in the as-built samples. The heat treatment caused a reduction in the lattice constant due to the precipitation of a large number of $\mathrm{NbC}$ and $\mathrm{MoC}$ carbides. The $\mathrm{MC}$ carbides formed due to heat treatment resulted in the formation of a zig-zag grain boundary that was crucial for the alloy ${ }^{30}$. Marchese et al. investigated the effect of various heat treatments on the mechanical behaviour and microstructure of the IN625 samples built by LPBF and compared the mechanical properties of the as-built samples and the heat-treated samples. It was observed that in the as-built samples, the presence of high dislocation density and the eutectic reactions resulted in the formation of very fine Nb-rich MC carbides (10-50 nm) in dendritic cores ${ }^{3}$. Kreitchberg et al. studied the effect of stress-relieving + HIPing on the microstructure and mechanical properties of LPBF built IN625 (layer thickness $=50 \mu \mathrm{m}$ ). It was observed that HIPing of LPBF built samples resulted in the dissolution of $\mathrm{M}_{6} \mathrm{C}$ carbides formed during stress relief treatment and formation of $\mathrm{MC}$ carbides along with equiaxed microstructure. It was observed that the anisotropy in the microstructure resulted in the lowest strength and highest elongation to failure in the vertically built specimens. However, the highest strength and lowest elongation to failure was observed for samples 
oriented along $45^{\circ}$ to the build direction and along the laser scan direction, respectively. The room temperature strength and elongation to failure of as-built samples were found to be higher or equal to wrought-annealed (WA) samples. However, the strength of as-built samples at $760^{\circ} \mathrm{C}$ was found to be comparable to that of WA samples and elongation at failure were found to be lesser than that of WA samples ${ }^{31}$. Post-processing techniques, like HIPing and solution treatment, were used primarily to close defects (cracks and pores) and dissolve undesirable phases by hindering diffusive transformation ${ }^{32-34}$. Applying HIPing or solution treatment could dissolve the $\delta$ phase and $\mathrm{M}_{6} \mathrm{C}$ carbides, respectively. HIPing + solution treatment reduced the anisotropy in mechanical properties by reducing the difference in the mechanical properties between the vertical and horizontal samples for stress relieved LPBF built IN625 samples and improved the ductility at room temperature. This was mainly due to the homogenization of microstructure during HIPing. At elevated temperatures, the presence of carbides along grain boundaries caused embrittlement of the solution treated and HIPed sample ${ }^{31}$. Hyer et al. carried out microstructural examinations on LPBF built IN625 thin and bulk samples before and after post-processing treatment (stress-relieving + HIPing + solution annealing). It was observed that $\mathrm{Nb}$ and Mo segregated along the intercellular boundaries along with the $\mathrm{A}_{2} \mathrm{~B}$ Laves phase and a small number of Al-rich oxide particles were uniformly distributed. Stress-relief + HIPing + solution annealing led to the formation of undesirable $\mathrm{M}_{6} \mathrm{C}$ carbides. Repeating the heat treatment at a higher HIPing temperature resulted in the dissolution of $\mathrm{M}_{6} \mathrm{C}$ carbides and the formation of $\mathrm{MC}$ carbides $^{35}$. Guo et al. studied the effect of solution treatment + HIPing on LPBF built IN625 (layer thickness $=40 \mu \mathrm{m}$ ) at both room and elevated temperatures and observed that the hardness of the LPBF built samples decreased after HIPing mainly due to depletion of $\mathrm{Nb}$ and Mo from the matrix to the interdendritic region ${ }^{36}$. Vernouillet et al. investigated the effect of stress-relieving + HIPing on LPBF built IN625 samples for thousands of hours in a $48 \% \mathrm{H}_{2}-9 \% \mathrm{CO}-6 \% \mathrm{CO}_{2}$ $3 \% \mathrm{CH}_{4}-34 \% \mathrm{H}_{2} \mathrm{O}$ atmosphere at $610^{\circ} \mathrm{C}$ for metal dusting and observed that HIPing led to an increase in metal dusting due to slowing of chromium diffusion towards the surface leading and favouring the formation of Fe-containing spinel oxide ${ }^{37}$. Son et al. performed creep tests on LPBF built IN625 in stress relieved + HIPed and as-built condition and detected $\mathrm{y}^{\prime \prime}$ along with $\mathrm{Al}_{2} \mathrm{O}_{3}$ ceramic inclusions in the as-built sample which were assigned the reason for lesser ductility during creep tests as compared to HIPed Wrought IN625 samples ${ }^{38}$. Poulin et al. investigated the effect of stress-relieving + HIPing on the fatigue crack propagation behaviour of LPBF built IN625 at room temperature. It was observed that the crack propagation behaviour of the HIPed specimens was nearly unaffected for both the build and the crack orientations $^{39}$.

In one of our recent endeavours, IN625 structures are successfully developed using LPBF at a higher layer thickness of $100 \mu \mathrm{m}^{40}$. Though there are many published literature about the deployment of HIPing on LPBF parts, these studies are pertaining to the lower layer thickness $(50 \mu \mathrm{m})$. Our literature survey shows that the HIPing of LPBF built IN625 samples built at higher layer thickness $(>50 \mu \mathrm{m})$ is not available in the open domain. HIP at higher layer thickness is relatively difficult due to a reduction in the ease of dislocation movement along the grain boundaries. This is mainly because of the reduction in the cooling rate during LPBF at higher layer thickness resulting in relatively coarser dendrites and hence fewer 
boundaries for the dislocations to travel along at high temperature and pressure during HIPing. Therefore, it is important to investigate the effect of HIPing on LPBF components built at higher layer thickness. Additionally, the literature reports HIPing on LPBF built samples being preceded by other heat treatments such as stress relief or solution treatment. This causes a change in the number of dislocations in the LPBF built part at the beginning of HIP and affecting the HIP. Further, limited comprehensive studies are explaining the effect of HIPing on the mechanical properties of LPBF IN625 structures. Thus, in this manuscript, a systematic investigation of direct effect of HIPing on the porosity, microstructure and mechanical properties of LPBF built IN625 structures at a higher layer thickness of $100 \mu \mathrm{m}$ is presented. In addition, the effect of HIPing and laser scan direction on the tensile properties are analysed and reported in this manuscript.

\section{Materials And Methods}

\subsection{Materials}

IN625 metal powder (Make: Powder Alloy Corporation, USA) with particle size ranging 15-45 $\mu \mathrm{m}$ is used as the feed material for the LPBF process. The chemical composition of IN625 powder provided by the powder manufacturer is presented in Table 1 . Sandblasted SS 304L substrate of $75 \mathrm{~mm}$ diameter and 10 $\mathrm{mm}$ thickness is used for processing.

Table 1. Chemical composition of IN625 powder used for LPBF

\begin{tabular}{|ll|}
\hline Element & Composition. \\
\hline $\mathrm{Cr}$ & 22.3 \\
\hline $\mathrm{Fe}$ & 4.8 \\
\hline $\mathrm{Mo}$ & 9.2 \\
\hline $\mathrm{Nb}+\mathrm{Ta}$ & 4.08 \\
$\mathrm{C}$ & 0.10 \\
$\mathrm{Al}$ & 0.38 \\
\hline $\mathrm{Ti}$ & 0.38 \\
\hline $\mathrm{Ni}$ & $\mathrm{Bal}$. \\
\hline
\end{tabular}

\subsection{LPBF and HIPing of IN625}

IN625 is deposited using an open architecture LPBF system having a build volume of $250 \mathrm{~mm} \times 250 \mathrm{~mm}$ $\times 250 \mathrm{~mm}$. The photograph and schematic diagram of the LPBF system is presented in Fig 1(a) and (b), respectively. The key components of the LPBF system are a $500 \mathrm{~W}$ fibre laser, galvano-scanner, build plate, powder-hopper, and powder re-coater controlled by a control unit. The movement of the laser beam 
on the powder bed/build platform is achieved by the galvano-scanner. The diameter of the laser beam spot on the top surface of the powder bed is $\sim 500 \mu \mathrm{m}$. IN625 blocks of size $25 \mathrm{~mm} \times 25 \mathrm{~mm} \times 15 \mathrm{~mm}$ are built at optimized process parameters of laser power $300 \mathrm{~W}$, scan speed $0.05 \mathrm{~m} \mathrm{~s}^{-1}$, and hatch spacing $0.250 \mathrm{~mm}$ with a higher layer thickness of $100 \mu \mathrm{m}$. More details on the process parameter optimization and selection are reported elsewhere ${ }^{40}$. The samples are built using a unidirectional scanning strategy.

Wire Electrical- Discharge Machining (WEDM) (Make: Concord, Model: DK-7732) is then used to extract the samples from the LPBF built structures. HIPing is carried out by soaking the sample at a temperature of $1100{ }^{\circ} \mathrm{C}$ and dwell for 1 hour at 1225 bar pressure and then ramped up to $1150{ }^{\circ} \mathrm{C} @ 3^{\circ} \mathrm{C}$ per minute followed by dwell at $1150^{\circ} \mathrm{C}$ for 3 hours at 1610 bar pressure and then allowed to cool to room temperature. Argon gas of purity grade 1 (purity $\geq 99.99 \%$ ) is used to apply pressure and prevent unwanted oxidation.

\subsection{Material Characterization and Testing}

LPBF built IN625 samples in as-built and HIPed conditions are sectioned using WEDM. The sectioned samples are cold mounted and subjected to polishing using emery paper with grit sizes ranging from 200 to 1000 . Subsequently, the mirror finish of the sample surfaces is obtained by cloth polishing with the help of a colloidal silica solution. An optical microscope (Make: Omnitech, Model: Metagraph) is used to obtain the images of the mirror-polished surfaces for porosity analysis. The porosity is analysed using the area fraction technique with the help of Image-J software. After porosity analysis, the samples are electrolytically etched at $12 \mathrm{~V}$ for $15 \mathrm{~s}$ in an etching solution with $10 \mathrm{~g}$ of oxalic acid and $100 \mathrm{ml}$ distilled water solution. The etched sample surfaces are studied using the optical microscope (Make: Omnitech, Model: Metagraph) and scanning electron microscope (SEM) (Make: Zeiss, Model: Supra55). Elemental mapping is carried out to understand the effect of HIPing on the precipitation and segregation of elements in LPBF built IN625 samples.

X-Ray Diffraction (XRD) of the samples is carried out using an X-ray diffractometer (Make: BRUKER, Model: D8 Advance) from $30^{\circ}$ to $110^{\circ}$ for identifying phases and estimating the size of the crystallites. Crystallites are sub-grains possessing lower misorientation angles and are equivalent to the microstructure domains that scatter X-rays coherently. Dwell time of $0.5 \mathrm{~s}$ and a step size of $0.02^{\circ}$ are used for the present XRD studies. Cu Ka radiation $(\lambda=1.54 \AA)$ is used at $40 \mathrm{~mA}$ and $40 \mathrm{kV}$ in a continuous scanning mode. From the XRD curves, Williamson-Hall $(\mathrm{W}-\mathrm{H})$ plots for the samples are obtained. W-H plot from XRD is obtained by plotting $\beta \cos (\theta)$ in $Y$-axis against $4 \sin (\theta)$ in $X$-axis and linearly interpolating them. The $Y$-axis intercept ' $C$ ' can be used to obtain the crystallite size ' $D$ ' using Equation $1^{41}$.

$$
D=\frac{0.9 \lambda}{c}
$$


The slope of the W-H plot gives lattice strain ' $\eta$ '.

The crystallite size and lattice strain can be used for estimating the average dislocation density ' $\rho$ ' using Equation 2.

$$
\rho=2 \sqrt{3} \frac{\eta}{D * b}
$$

Where, $b$ represents the burger's vector and for IN625 it is equal to $0.179 \mathrm{~nm}^{42}$.

Fig 2 shows the schematic of LPBF building strategy indicating the front section and the side section with respect to the scan direction on the built sample. The build direction, laser scan direction, front section and side section are labelled in Fig 2 .

Micro-tensile test specimens are extracted from both as-built and HIPed samples normal to the laser scan direction and along the laser scan direction. The dimensions of the micro-tensile test specimens are given in Fig $3^{40}$. A Vickers microhardness tester (Make: Omnitech, Model: MVH-SAuto) is used to measure the micro-hardness of both as-built and HIPed samples. The load and dwell time of the micro-hardness tester is set at $100 \mathrm{~g}$ and 10 seconds, respectively. Average micro-hardness is obtained from the indentations taken at six different positions on the polished surfaces of the samples. Automated Ball Indentation $\left(\mathrm{ABI}{ }^{\circledR}\right)$ studies for the single cycle are carried out using an Automated Ball Indenter (Make: BISS, Model: AC-04-2370-05) machine to determine the indentation depth and estimate the material's energy storage capability ${ }^{43}$. The maximum load and a loading rate of $80 \mathrm{~N}$ and $0.1 \mathrm{~mm} / \mathrm{min}$, respectively is used for carrying out $A B I^{\circledR}$ studies. Before performing the actual testing, a $5 \mathrm{~N}$ preload is used. The applied load is unloaded to $10 \mathrm{~N}$ after the dwell time.

\section{Results And Discussion}

\subsection{Porosity Analysis}

Figs 4(a) and 4(b) present the typical cross-section images of the as-built samples showing irregular porosity and HIPed samples, respectively. The measured average porosity in the as-built sample using area fraction technique is $0.43 \%$, which primarily are irregularly shaped pores (marked 1 in Fig $4(a)$ ) and after HIPing the average porosity is found to be $\sim 0.01 \%$ (Fig 4(b)). The number of irregular pores is more in as-built samples as compared to the circular pores. The irregular shaped pores are process-induced and are primarily generated due to lack of fusion. They are produced either due to incomplete coalescence of molten metal powder or due to the turbulence in the melt-pool creating voids because of the splashing of the melt-pool. A similar observation is reported by Qiu et al. ${ }^{44}$. As the present work is focused on higher layer thickness, LPBF built samples have predominantly irregular porosity because of the following phenomena. When the laser beam strikes the top surface of the powder, it gets melted instantly and the powder particles beneath are melted due to heat energy transferred through thermal conductivity. As the thermal conductivity of the powder is much lower than the solid metal due to a 
packing density of $\sim 80 \% 45$, it generates a turbulent melt-pool on the powder bed leading to the generation of voids or pores in the melt-pool. The accumulated heat during laser scanning enhances the recoil pressure and Marangoni effect and leads to the generation of voids/pores. Marangoni effect is the phenomenon, where the gradient in the surface tension causes transfer of fluid mass from low to high surface tension region. This change in surface tension can be caused due to gradient in temperature inside the melt-pool ${ }^{46}$. It may also be noted that the recoil pressure is generated when the region under the laser gets heated up beyond the boiling point of the metal, which results in the generation of metallic vapours over the melt-pool surface that in turn applies pressure on the melt-pool, affecting its shape ${ }^{47}$.

Fig 5 shows the mechanism of void formation from recoil pressure effects during LPBF. As shown in Fig. 5 , the generation of recoil pressure creates a localised depression over the melt-pool at the point of consideration. However, once the laser moves away from the point under consideration, the melt-pool temperature goes below the boiling point yielding no recoil pressure. Thereafter, the Marangoni causes the molten metal to flow and fill the depression created earlier due to the recoil pressure. If the cooling rate is very high, sufficient time will not be available for the complete filling of the depression, resulting in the formation of voids/pores. Besides this, irregularly shaped pores/voids can also be generated by powder particle agglomeration. Restricted heat dissipation due to higher layer thickness increases the melt-pool surface temperature, which induces convective air currents in the immediate atmosphere. Typically, the time duration for these convective currents is in the order of tens of milliseconds ${ }^{48}$. These convective currents drag powder particles from the melt-pool surroundings into the melt-pool resulting in denudation. The denudation causes partially fused power/agglomerated powder to be pulled towards and getting trapped inside the melt-pool. These agglomerated powders during cool-down generate porosity. Higher layer thickness also increases the probability of improper bonding of the molten material with the previously built layer, which in turn can lead to pore/void formation.

When LPBF samples are subjected to HIPing, the stress is applied from all directions resulting in a viscoplastic flow of the metal. This flow of metal fills up the pores/voids generated during LPBF. As HIPing is carried out at an elevated temperature, the LPBF built IN625 experiences a reduction in yield stress. Plastic deformation of IN625 begins when the yield stress at the elevated temperature decreases below the inert gas pressure during HIPing. The plastic flow occurs on a microscopic level at very high rates following different creep deformation mechanisms such as Nabarro-Herring creep, Coble creep mechanisms that can be attributed to diffusion through grain interiors, around grain boundaries and dislocation creep ${ }^{49}$.In this way, HIPing results in a significant reduction in void/pores in the as-built samples.

\subsection{Microstructure Examination}

Fig 6 (a) - 6 (c) present the microstructures of the as-built samples obtained using an optical microscope. In Fig 6 (a), the etched surfaces of the as-built samples show visible melt-pool boundaries. These melt-pool boundaries in the as-built sample are mainly generated due to the re-melting and resolidification of the previously built layers during LPBF process. Also, the microstructure growth of the as- 
built samples is columnar with cellular/ dendritic growth. The mixed cellular and dendritic growth are primarily due to the favouring thermal gradient at the solidification front during LPBF. Initially, the build plate/ substrate is at room temperature and it acts as a sink. During the first layer deposition, the thermal gradient is very high that causes cellular growth at the bottom layers as shown in Fig 6 (b). However, as the layers build up dendritic growth with classical secondary arms are also seen due to the lower thermal gradient as shown in Fig 6 (c). Generally, finer microstructures are observed in the LPBF built samples due to the high cooling rate during LPBF. The typical cooling rate in LPBF is around $10^{6}{ }^{\circ} \mathrm{C} / \mathrm{s}^{3}$. It is also seen that the microstructural growth spans across multiple melt-pool boundaries at several locations as marked in Fig 6 (a). This is because melt-pool possesses enough energy to promote the growth of the grains in alignment with the grains in the adjacent region in the previous layer resulting in epitaxial growth. This effect can also be attributed to the higher thermal energy retained in the melt-pool for a relatively long period because of the higher layer thickness that results in relatively lower effective thermal conductivity.

Fig 7 presents the microstructure of the HIPed samples. It can be seen that there are no melt-pool boundaries as they are annihilated during HIPing treatment due to solutionizing effects. The solutionizing effect involves recrystallization and grain growth. It begins from the grain boundaries because these are high energy sites. The grains grow and dissolve the earlier formed microstructure. This is evident from the transformation of equiaxed growth to cellular/dendritic growth. The measured average grain size in the HIPed sample is $31 \mu \mathrm{m}$. During HIPing, the coalescence of dendrites leads to the formation of the coarse equiaxed grains. It can also be seen that the second phase precipitates of variable sizes are observed along the grain boundaries.

Fig 8 illustrates the elemental mapping of as-built and HIPed samples. The segregation of $\mathrm{Nb}, \mathrm{Si}$ and $\mathrm{C}$ is observed in the as-built sample as presented in Fig 8(a). However, the combination of $\mathrm{Ni-Nb}$ is not observed in as-built samples due to the depletion of $\mathrm{Ni}$ at $\mathrm{Nb}$-rich regions. Thus, the generation of the $\delta$ $\left(\mathrm{Ni}_{3} \mathrm{Nb}\right)$ phase could not be confirmed in the as-built samples. Further, a combination of $\mathrm{Nb}-\mathrm{C}$ is observed at some locations, which may be due to the formation of Nb-rich carbides during the LPBF of IN625. The formation of $\mathrm{Nb}$-rich carbides can be because of thermal cycles during the successive layer by layer fabrication. This is in line with the work by Keller et al. in which thermodynamic calculations are carried out for determining the driving force for nucleation of secondary phases in the interdendritic zones ${ }^{50}$. Nbrich carbides can nucleate first either from the $\mathrm{y}$-matrix that is supersaturated with $\mathrm{Nb}$ or precipitate directly from the liquid phase. Dupont et al. explained that $\mathrm{Nb}$ segregates strongly during solidification and its formation can be understood with the help of the following reaction ${ }^{51}$ :

\section{$\mathrm{L} \rightarrow \gamma+\mathrm{NbC}$}

Fig 8 (b) presents the elemental mapping of HIPed samples. Elemental segregations of $\mathrm{Mo}, \mathrm{Si}, \mathrm{Cr}, \mathrm{Nb}$ and $\mathrm{C}$ are observed. The tendency for higher segregation in the HIPed samples are primarily due to a lower cooling rate during HIPing. The formation of carbides rich with $\mathrm{Nb}, \mathrm{Mo}$ and $\mathrm{Cr}$ are also detected in the 
HIPed samples. This can be due to the lower cooling rate after HIPing, which provided sufficient time for $\mathrm{Nb}, \mathrm{Mo}$ and $\mathrm{Cr}$ to react with $\mathrm{C}$ to form carbides and precipitate.

Fig 9 represents the XRD plots obtained for as-built and HIPed IN625 samples. It is observed that XRD of as-built samples and HIPed samples show peaks corresponding to the $\mathrm{Y}$-Ni matrix. However, the presence of $\mathrm{Nb}$-rich carbides detected in the as-built samples and $\mathrm{Nb}, \mathrm{Mo}, \mathrm{Cr}$ based carbides present in the HIPed samples are not observed during XRD analysis. This can be due to the lower volume fraction of these phases. Further, Equation 2 is used to quantify the effect of HIPing on the dislocation density, which is a function of crystallite size and microstrain in the material. The crystallite size and the microstrain are estimated using the W-H. Fig 10 (a) and (b) presents the W-H plot obtained from the XRD of LPBF built samples in as-built and HIPed conditions.

From the W-H plot, the crystallite sizes are calculated using Equation 1 for as-built IN625 samples and HIPed samples and they are found as $40 \mathrm{~nm}$ and $207 \mathrm{~nm}$, respectively. The larger average crystallite size is observed for the HIPed samples mainly due to the coalescence of fine crystallites into coarse crystallites during HIPing. Further, the reduction in the number of low angle grain boundaries during the HIPing process may also result in the formation of larger crystallites as the samples are kept at an elevated temperature for a sufficiently long period.

It is also observed that the dislocation density calculated using Equations 2 and 3 for as-built IN625 samples and HIPed samples are $6.74 \times 10^{14} \mathrm{~m}^{-2}$ and $2.06 \times 10^{14} \mathrm{~m}^{-2}$, respectively. Thus, the dislocation density of the as-built samples is greater than three times that of the corresponding HIPed samples. This is because the elevated temperature during HIPing facilitates the easy movement of the dislocations. The dislocations with opposite burger vectors annihilate each other and in turn, the number of dislocations reduces ${ }^{52}$.

\subsection{Effect of HIPing on Mechanical Properties}

Table 2: Yield strength, ultimate tensile strength and ductility of as-built and HIPed samples. 


\begin{tabular}{|c|c|c|c|}
\hline Sample & $\begin{array}{l}\text { YS } \\
(\mathrm{MPa})\end{array}$ & $\begin{array}{l}\text { UTS } \\
\text { (MPa) }\end{array}$ & $\%$ El \\
\hline \multirow[t]{2}{*}{ WA 53} & 482 & 955 & 41 \\
\hline & & & $\begin{array}{l}\text { (20 mm gauge } \\
\text { length) }\end{array}$ \\
\hline \multirow{2}{*}{$\begin{array}{l}\text { As-built extracted along the laser scan (present } \\
\text { work) }\end{array}$} & 671 & 969 & 11.9 \\
\hline & & & $\begin{array}{l}\text { (3 mm gauge } \\
\text { length) }\end{array}$ \\
\hline \multirow{2}{*}{$\begin{array}{l}\text { As-built extracted normal to the laser scan (present } \\
\text { work) }\end{array}$} & 786 & 1053 & 8.11 \\
\hline & & & $\begin{array}{l}\text { (3 mm gauge } \\
\text { length) }\end{array}$ \\
\hline \multirow[t]{2}{*}{ HIPed and extracted along the laser scan } & 466 & 846 & 17.45 \\
\hline & & & $\begin{array}{l}(3 \mathrm{~mm} \text { gauge } \\
\text { length) }\end{array}$ \\
\hline \multirow[t]{2}{*}{ HIPed and extracted normal to the laser scan } & 457 & 804 & 12.70 \\
\hline & & & $\begin{array}{l}\text { (3 mm gauge } \\
\text { length) }\end{array}$ \\
\hline
\end{tabular}

It is observed that the YS and the UTS of IN625 in the WA condition are lower than that of the as-built samples and higher than that of the HIPed samples. This is because the HIPed samples have coarser microstructure relative to the WA samples and the WA samples have coarser microstructure than the asbuilt samples. As mentioned earlier, the grain size of the HIPed sample is $31 \mu \mathrm{m}$, while the grain size of the WA sample reported in the literature is $15 \mu \mathrm{m}^{53}$. It is observed that the YS and the UTS of the HIPed samples are lower than that of the corresponding as-built sample values. At the same time, an increase in ductility after HIPing is also observed. This can be primarily because of the reduction in the dislocation density after HIPing. The coarse grains in the HIPed sample as compared to the fine dendrites in the asbuilt sample also contribute to the decreased mechanical strength and increased ductility of the HIPed samples. The decrease in the dislocation density after HIPing yields less resistance to the external load resulting in lower strength and higher ductility after HIPing. It is expected that the decrease in strength after HIPing will be reflected in the hardness tests and the ABI® tests. The ductility $\left(e_{f}\right)$ of the HIPed samples taken along the laser scan (17.45\%) and taken normal to the laser scan (12.70\%) are more than that of the corresponding samples in as-built samples. This can be attributed to the reduction in porosity, presence of coarser grains and reduction in the dislocation density after HIPing. The effect of coarser grains and reduced dislocation density on the mechanical properties of the HIPed sample in comparison to the as-built sample is already discussed earlier. These cooling rates are high enough to result in finer grains as compared to the WA samples, but at the same time, the grain size is coarser than the as-built samples as LPBF processed samples experience relatively higher cooling rates. 
It is observed that the elongation of the sample taken along the laser scan $(11.9 \%)$ is larger than that of the sample taken normal to the laser scan $(8.11 \%)$ for the as-built samples. This can be attributed to the direction of the applied load concerning the boundaries formed from the overlapping tracks in an individual layer. For the samples taken normal to the laser scan direction, when the tensile load is applied, the dislocations have to encounter the melt-pool boundaries formed from the overlapping zones of the adjacent tracks, which act as sinks for void coalescence. For the samples taken along the laser scan direction, the dislocations do not encounter the melt-pool boundaries with overlapping tracks and can have relatively easily movement avoiding the sinks for void coalescence and hence give rise to the relatively higher ductility. In the case of the HIPed samples, YS, UTS and elongation for the sample taken along the laser scan direction and the sample taken normal to the laser scan direction, show lesser variation within $10 \%$. This can be due to the equiaxed nature of the grains formed after HIPing, which results in isotropy in the sample.

Fig 11 presents the stress-strain curves obtained from the tensile tests for LPBF built IN625 samples in both as-built and HIPed conditions for samples extracted along and normal to the laser scan direction. Table 2 presents the yield stress (YS), ultimate tensile stress (UTS) and the percentage elongation/ ductility (\%EI) obtained from tensile test results.

Fig 12 presents the micro-hardness of the as-built and HIPed samples taken on both front and side sections of the samples along with that of the WA samples obtained from the literature ${ }^{53}$. Microhardness of the HIPed samples are found to be lower than that of the as-built samples, but similar to the WA samples. The lower hardness of HIPed samples can be attributed to the coarser grain size and lower dislocation density as compared to the as-built samples. The coarser grain size and the lower dislocation density provide lower resistance during plastic deformation, which leads to a reduction in micro-hardness after HIPing. As mentioned earlier, this reduction in the hardness after HIPing is also reflected in the tensile test studies. It is also observed that the deviation in the hardness values reduced after HIPing treatment. This can be attributed to the isotropic nature of the HIPed sample. Also, the micro-hardness of HIPed samples is found to be close to the micro-hardness of conventionally built IN625 bar in the annealed condition. The micro-hardness values are similar on the front section and side section of the asbuilt samples as well as HIPed samples. The similar values of micro-hardness between WA and HIPed samples are primarily due to the presence of coarse equiaxed grains and reduced dislocation density in HIPed samples.

Fig 13 presents the load vs. displacement curve obtained from single-cycle automated ball indentation for IN625 as-built and HIPed samples on both front and side sections. The area under the curve is representative of the amount of energy that can be stored by a material, while the maximum displacement of the intender at a particular load is a function of the hardness or the resistance to deformation. It is observed that the maximum indenter displacement is higher for HIPed samples in comparison to that of as-built samples. The obtained maximum displacement values for the as-built front, as-built side, HIPed front and HIPed side are $0.0450 \mathrm{~mm}, 0.0476 \mathrm{~mm}, 0.0495 \mathrm{~mm}$ and $0.0491 \mathrm{~mm}$, respectively. It is also observed that the area under the curve for the as-built samples are lower than the 
area under the curve for HIPed samples. The measured area under the curve for the as-built front, as-built side, HIPed front and HIPed side are $0.286 \mathrm{~N}-\mathrm{mm}, 0.341 \mathrm{~N}-\mathrm{mm}, 0.408 \mathrm{~N}-\mathrm{mm}$ and $0.391 \mathrm{~N}-\mathrm{mm}$, respectively. The reason for higher indenter displacement and the area under the curve for the HIPed sample can be attributed to its coarse grain structure and relatively reduced dislocation density. The presence of coarse grains reduces the number of grain boundaries encountered by the dislocations for HIPed samples. Further, due to lower dislocation density, the hindrance for dislocation movement is also reduced in HIPed samples. The relatively unhindered motion of the dislocations in the HIPed sample results in higher indenter displacement and higher area under the curve. In contrast, the reason for such lower indenter displacement and the area under the curve for the as-built sample can be attributed to its fine grain structure and relatively higher dislocation density. Because of fine grains, the dislocations have more sites or grain boundaries for them to get annihilated during plastic deformation. The dislocation movement during plastic deformation is also hindered by the relatively larger dislocation density. Both these reasons lead to relatively lower resistance or lower indentation depth and lower area under the curve for the as-built sample. The maximum displacement values and the area under the curve obtained from single-cycle automated ball indentation on the front section and side section are closer for the HIPed samples as compared to that for the as-built samples. This can be attributed to the formation of equiaxed grains in the HIPed sample yielding improved isotropy as opposed to the columnar grain structure in the as-built sample.

\section{Conclusions}

In the present work, LPBF built IN625 samples are subjected to HIPing treatment and the effect of HIPing on the porosity, microstructure and mechanical properties are investigated using a systematic study and the following are concluded:

1. The as-built samples revealed the presence of process-induced pores/voids, which reduced significantly in size and numbers after HIPing treatment. The estimated porosity in as-built and HIPed samples are $0.43 \%$ and $0.01 \%$, respectively.

2. The microstructure of as-built samples reveals melt-pool boundaries and a combination of cellular growth and dendritic growth, while the HIPed sample reveals coarse equiaxed grains without meltpool boundaries.

3. Elemental mapping reveals that Si gets elementally segregated and the Nb-rich carbides get precipitated of in the as-built samples. While, elemental segregations of Si are observed along with precipitation of $\mathrm{Nb}, \mathrm{Mo}$ and $\mathrm{Cr}$ rich carbides in the HIPed samples. XRD reveals the presence of $\mathrm{Y}$ phase in both cases with no peaks corresponding to precipitates due to their presence in low volume fractions. The estimated dislocation density from XRD analysis is $6.74 \times 10^{14} \mathrm{~m}^{-2}$ and $2.06 \times 10^{14} \mathrm{~m}^{-2}$ for as-built and HIPed samples, respectively.

4. HIPed samples that are extracted along the laser scan direction and normal to laser scan direction show lower strength and higher ductility than the corresponding as-built samples. Additionally, the YS and UTS of the HIPed samples are found to be slightly less than those of the WA samples.

Page 13/30 
However, anisotropy is observed in the mechanical properties of as-built samples, while the HIPed samples show isotropic behaviour.

5. Vickers micro-hardness and $A B I^{\circledR}$ studies reveal that the HIPed samples have lower resistance to plastic deformation than the as-built material due to grain coarsening and reduction in dislocation density. Also, the ability to store energy during deformation is observed to be higher for HIPed samples in comparison to the as-built samples. The hardness values of the HIPed samples are found to be close to the hardness of the WA samples reported in the literature.

Thus, HIPing is a suitable method for building dense and isotropic IN625 components near net-shaped. This study will pave a way for the fabrication of defect-free, isotropic and dense functional Ni-based superalloy components using higher layer thickness LPBF followed by the HIP.

\section{Declarations}

\section{Acknowledgements}

The authors thank Dr A K Rai, Mr C S Mandloi, Mr A. Adbol, Mr S.Tudu, Mr Lalit, Mr S Yadav and Mr K Dileep of LAM Lab, RRCAT for their help in sample preparation and micro-hardness testing. The authors thank Deputy Director, Materials and Mechanical Entity and Materials Technology Division and Hot Isostatic Press Facility divisions in VSSC, Thiruvananthapuram for extending facility/research support for micro-tensile testing and HIP facilities for the work reported in this manuscript and thank the Director, VSSC for permitting to publish this work.

\section{Author contribution}

\section{Author's Name Individual Contributions}

Saurav Kumar Nayak Conceptualization; Investigation; Data Curation; Formal analysis; Writing original draft

Arackal Narayanan Investigation; Methodology; Writing - review \& editing Jinoop

Christ Prakash Paul Conceptualization; Methodology; Supervision; Writing - review \& editing; Resources;

Vesangi Anil Kumar Investigation; Resources; Writing - review \& editing

S Dineshraj Resources; Writing - review \& editing

Rashmi Singh

Resources; Writing - review \& editing

Kushvinder Singh

Bindra

Writing - review \& editing; Project administration; Resources

Funding This study was funded by Raja Ramanna Centre for Advanced Technology (RRCAT), Department of Atomic Energy and Vikram Sarabhai Space Centre, Department of Space, Government of India. 
Data Availability Data will be made available upon request.

Code availability Not applicable.

Ethical approval No ethical approval was required for this research.

Consent to participate The consent for participation has been acquired from all the participants.

Consent for publication Work has consent to publish from all the participants.

Conflict interest The authors declare no competing interests relevant to the content of this manuscript.

\section{References}

1. Jinoop AN, Paul CP, Bindra KS(2019) Laser-assisted directed energy deposition of nickel super alloys: A review. Proceedings of the IMechE 233: 2376-2400.

2. Fan W, Ji W, Wang L, et al(2020) A review on cutting tool technology in machining of Ni-based superalloys() Int J Adv Manuf Technol 110: 2863-2879.

3. Marchese G, Lorusso M, Parizia S, et al(2018) Influence of heat treatments on microstructure evolution and mechanical properties of Inconel 625 processed by laser powder bed fusion. Materials Science and Engineering: A 729: 64-75.

4. Pleass C, Jothi S(2018) Influence of powder characteristics and additive manufacturing process parameters on the microstructure and mechanical behaviour of Inconel 625 fabricated by Selective Laser Melting. Additive Manufacturing 24: 419-431.

5. Ramenatte N, Vernouillet A, Mathieu S, et al(2020) A comparison of the high-temperature oxidation behaviour of conventional wrought and laser beam melted Inconel 625. Corrosion Science 164: 108347.

6. Benoit MJ, Mazur M, Easton MA, et al(2021) Effect of alloy composition and laser powder bed fusion parameters on the defect formation and mechanical properties of Inconel 625. Int J Adv Manuf Technol 114: 915-927.

7. Gola K, Dubiel B, Kalemba-Rec I(2020) Microstructural Changes in Inconel 625 Alloy Fabricated by Laser-Based Powder Bed Fusion Process and Subjected to High-Temperature Annealing. $J$ of Materi Eng and Perform 29: 1528-1534.

8. Marchese G, Parizia S, Rashidi M, et al(2020) The role of texturing and microstructure evolution on the tensile behavior of heat-treated Inconel 625 produced via laser powder bed fusion. Materials Science and Engineering: A 769: 138500. 
9. Jinoop AN, Paul CP, Nayak SK, et al(2021) Effect of laser energy per unit powder feed on Hastelloy-X walls built by laser directed energy deposition based additive manufacturing. Optics \& Laser Technology 138: 106845.

10. Yadav S, Paul CP, Jinoop AN, et al(2020) Laser Directed Energy Deposition based Additive Manufacturing of Copper: Process Development and Material Characterizations. Journal of Manufacturing Processes 58: 984-997.

11. Shrestha S, Chou K(2021) A study of transient and steady-state regions from single-track deposition in laser powder bed fusion. Journal of Manufacturing Processes 61: 226-235.

12. Cheng B, Chou K(2020) A numerical investigation of support structure designs for overhangs in powder bed electron beam additive manufacturing. Journal of Manufacturing Processes 49: 187-195.

13. Resnina N, Palani IA, Belyaev S, et al(2021) Structure, martensitic transformations and mechanical behaviour of NiTi shape memory alloy produced by wire arc additive manufacturing. Journal of Alloys and Compounds 851: 156851.

14. Nayak SK, Mishra SK, Paul CP, et al(2020) Effect of energy density on laser powder bed fusion built single tracks and thin wall structures with $100 \mu \mathrm{m}$ preplaced powder layer thickness. Optics \& Laser Technology 125: 106016.

15. Ye W, Bao J, Lei J, et al(2021) Multiphysics Modeling of Thermal Behavior of Commercial Pure Titanium Powder During Selective Laser Melting. Met Mater Int. Epub ahead of print. DOI: 10.1007/s12540-021-01019-1.

16. Gerstgrasser M, Cloots M, Stirnimann J, et al(2021) Residual stress reduction of LPBF-processed CM247LC samples via multi laser beam strategies. Int J Adv Manuf Technol. Epub ahead of print. DOI: 10.1007/s00170-021-07083-6.

17. Erturk AT, Bulduk ME, Tarakçi G, et al(2021) Investigation of the Microstructure and Mechanical Characteristics of Lattice Structures Produced by Laser Powder Bed Fusion Method. Met Mater Int. Epub ahead of print 10 September. DOI: 10.1007/s12540-021-01038-y.

18. Zhang Y, Yang S, Zhao YF(2020) Manufacturability analysis of metal laser-based powder bed fusion additive manufacturing-a survey. Int J Adv Manuf Technol 110: 57-78.

19. Salarian $\mathrm{M}, \mathrm{Asgari} \mathrm{H}$, Vlasea $\mathrm{M}(2020)$ Pore space characteristics and corresponding effect on tensile properties of Inconel 625 fabricated via laser powder bed fusion. Materials Science and Engineering: A 769: 138525.

20. Olleak A, Xi Z(2021) A study of modeling assumptions and adaptive remeshing for thermomechanical finite element modeling of the LPBF process. Int J Adv Manuf Technol 115: 35993615 .

Page 16/30 
21. Benarji K, Ravi Kumar Y, Jinoop AN, et al(2021) Effect of Heat-Treatment on the Microstructure, Mechanical Properties and Corrosion Behaviour of SS 316 Structures Built by Laser Directed Energy Deposition Based Additive Manufacturing. Met Mater 27: 488-499.

22. Jahns K, Bappert R, Böhlke P, et al(2020) Additive manufacturing of CuCr1Zr by development of a gas atomization and laser powder bed fusion routine. Int J Adv Manuf Technol 107: 2151-2161.

23. Chadha K, Tian Y, Spray J, et al(2021) Microtextural Characterization of Additively Manufactured SS316L After Hot Isostatic Pressing Heat Treatment. Met Mater Int. Epub ahead of print. DOI:

10.1007/s12540-021-01046-y.

24. Ganesh MRS, Reghunath N, J.Levin M, et al(2021) Strontium in Al-Si-Mg Alloy: A Review. Met Mater Int. Epub ahead of print 5 October. DOI: 10.1007/s12540-021-01054-y.

25. Aryanpour G, Mashl S, Warke V(2013) Elastoplastic-viscoplastic modelling of metal powder compaction: application to hot isostatic pressing. Powder Metallurgy 56: 14-23.

26. Liverani E, Lutey AHA, Ascari A, et al(2020) The effects of hot isostatic pressing (HIP) and solubilization heat treatment on the density, mechanical properties, and microstructure of austenitic stainless steel parts produced by selective laser melting (SLM). Int J Adv Manuf Technol 107: 109-122.

27. Liu H, Wang L, Jiang Y, et al(2018) Study on SiO2 thin film modified by post hot isostatic pressing. Vacuum 148: 258-264.

28. Paul CP, Jinoop AN, Nayak SK, et al(2020) Laser Additive Manufacturing in Industry 4.0: Overview, Applications, and Scenario in Developing Economies. In: Balasubramanian KR, Senthilkumar V ( $1^{\text {st }}$ eds) Additive Manufacturing Applications for Metals and Composites: IGI Global, Trichy, pp. 271295.

29. Hu X, Xue Z, Ren T, et al(2020) On the fatigue crack growth behaviour of selective laser melting fabricated Inconel 625: Effects of build orientation and stress ratio. Fatigue Fract Eng Mater Struct 43: 771-787.

30. Li S, Wei Q, Shi Y, et al() Microstructure Characteristics of Inconel 625 Superalloy Manufactured by Selective Laser Melting. Journal of Materials Science \& Technology 31: 946-952.

31. Kreitcberg A, Brailovski V, Turenne S(2017) Elevated temperature mechanical behavior of IN625 alloy processed by laser powder-bed fusion. Materials Science and Engineering: A 700: 540-553.

32. Wang Y, Yang J, Huang J, et al(2018) Hot isostatic diffusion bonding tungsten alloy and highstrength steel Part I: Design and preparation of Ni-Si-B interlayer by magnetron sputtering. Journal of Manufacturing Processes 35: 360-367. 
33. Kang N, Lu JL, Li QG, et al(2020) A new way to net-shaped synthesis tungsten steel by selective laser melting and hot isostatic pressing. Vacuum 179: 109557.

34. Sarkar S, Mukherjee S, Kumar CS, et al(2020) Effects of heat treatment on microstructure, mechanical and corrosion properties of $15-5 \mathrm{PH}$ stainless steel parts built by selective laser melting process. Journal of Manufacturing Processes 50: 279-294.

35. Hyer H, Newell R, Matejczyk D, et al(2021) Microstructural Development in As Built and Heat Treated IN625 Component Additively Manufactured by Laser Powder Bed Fusion. J Phase Equilib Diffus 42: 14-27.

36. Guo X, Ling H, Huang X(2020) Effect of HIP treatment on the microstructure and mechanical properties of a Ni-based superalloy fabricated by selective laser melted method. $J$ Phys: Conf Ser 1605: 012143.

37. Vernouillet A, Vande Put A, Pugliara A, et al(2020) Metal dusting of Inconel 625 obtained by laser beam melting: Effect of manufacturing process and hot isostatic pressure treatment. Corrosion Science 174: 108820.

38. Son K-T, Kassner ME, Lee KA(2020) The Creep Behavior of Additively Manufactured Inconel 625 . Advanced Engineering Materials 22: 1900543.

39. Poulin J-R, Brailovski V, Terriault P(2018) Long fatigue crack propagation behavior of Inconel 625 processed by laser powder bed fusion: Influence of build orientation and post-processing conditions. International Journal of Fatigue 116: 634-647.

40. Nayak SK, Mishra SK, Jinoop AN, et al(2020) Experimental Studies on Laser Additive Manufacturing of Inconel-625 Structures Using Powder Bed Fusion at $100 \mu \mathrm{m}$ Layer Thickness. J of Materi Eng and Perform. Epub ahead of print. DOI: 10.1007/s11665-020-05215-9.

41. Razavi M, Irankhah R, Rahimipour MR(2015) Effect of milling of $C$ and Ti mixture as ceramic coating on the properties of $7 \mathrm{Ch} 3$ tool steel during plasma spray process. Proceedings of the Institution of Mechanical Engineers, Part L: Journal of Materials: Design and Applications 229: 137-145.

42. Gao Y, Zhou M(2018) Superior Mechanical Behavior and Fretting Wear Resistance of 3D-Printed Inconel 625 Superalloy. Applied Sciences 8: 2439.

43. Jinoop AN, Denny J, Paul CP, et al(2019) Effect of post heat-treatment on the microstructure and mechanical properties of Hastelloy-X structures manufactured by laser based Directed Energy Deposition. Journal of Alloys and Compounds 797: 399-412.

44. Qiu C, Panwisawas C, Ward M, et al(2015) On the role of melt flow into the surface structure and porosity development during selective laser melting. Acta Materialia 96: 72-79. 
45. King WE, Anderson AT, Ferencz RM, et al(2015) Laser powder bed fusion additive manufacturing of metals; physics, computational, and materials challenges. Applied Physics Reviews 2: 041304.

46. Niu S, Yin K, You Q, et al(2019) The alloying elements dispersion and its mechanisms in a Nibased superalloy during electron beam remelting. Vacuum 166: 107-113.

47. Yang Z, Fang Y, He J(2020) Numerical simulation of heat transfer and fluid flow during vacuum electron beam welding of 2219 aluminium girth joints. Vacuum 175: 109256.

48. Bidare P, Bitharas I, Ward RM, et al(2018) Fluid and particle dynamics in laser powder bed fusion. Acta Materialia 142: 107-120.

49. Atkinson HV, Davies S(2000) Fundamental aspects of hot isostatic pressing: An overview. Metall and Mat Trans A 31: 2981-3000.

50. Keller T, Lindwall G, Ghosh S, et al(2017) Application of finite element, phase-field, and CALPHAD-based methods to additive manufacturing of Ni-based superalloys. Acta Materialia 139: 244253.

51. DuPont JN(1996) Solidification of an alloy 625 weld overlay. Metall Mater Trans A 27: 36123620 .

52. Tong X, Zhang H, Li DY(2015) Effect of Annealing Treatment on Mechanical Properties of Nanocrystalline a-iron: an Atomistic Study. Sci Rep 5: 8459.

53. Nguejio J, Szmytka F, Hallais S, et al(2019) Comparison of microstructure features and mechanical properties for additive manufactured and wrought nickel alloys 625. Materials Science and Engineering: A 764: 138214.

\section{Figures}




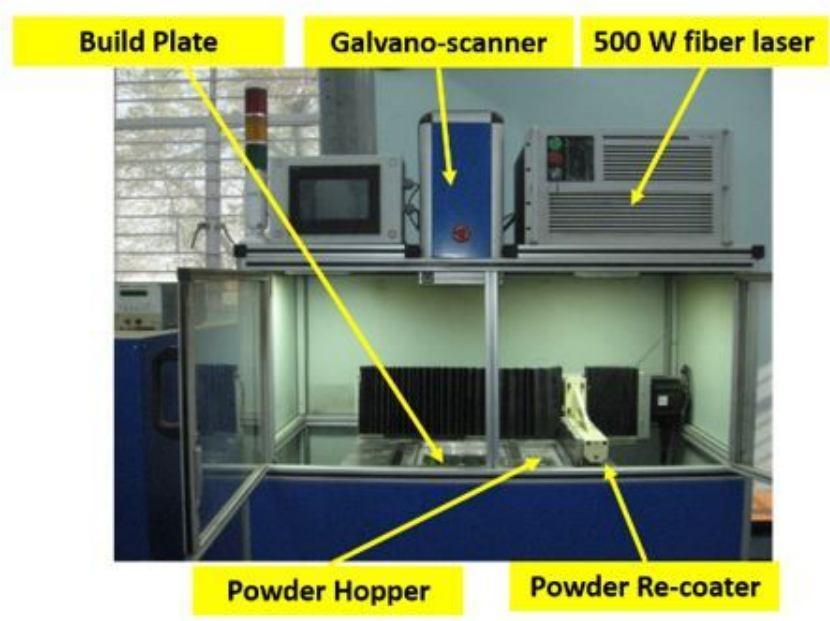

(a)

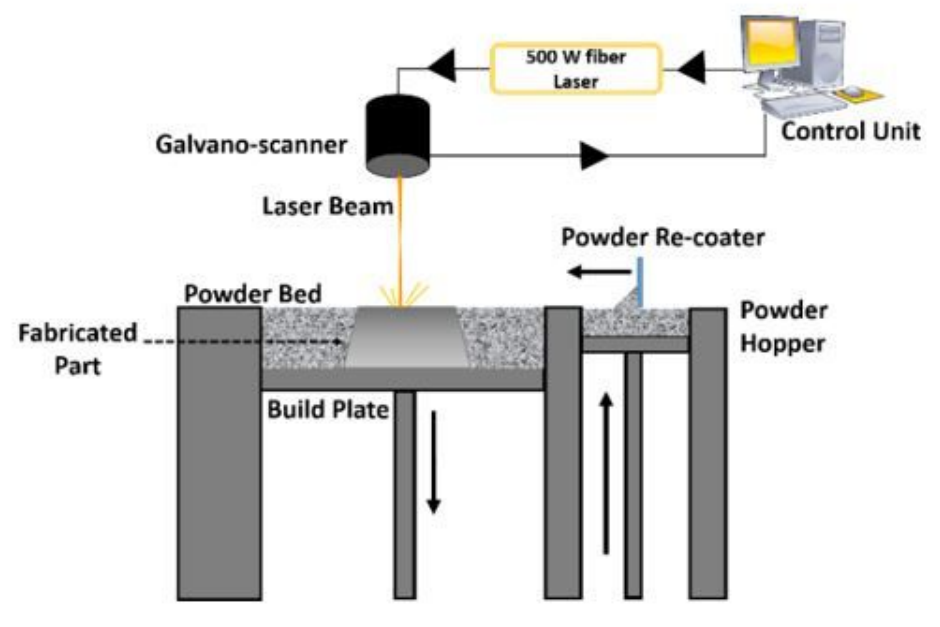

(b)

\section{Figure 1}

Indigenously developed LPBF system: (a) Photograph (b) Schematic representation

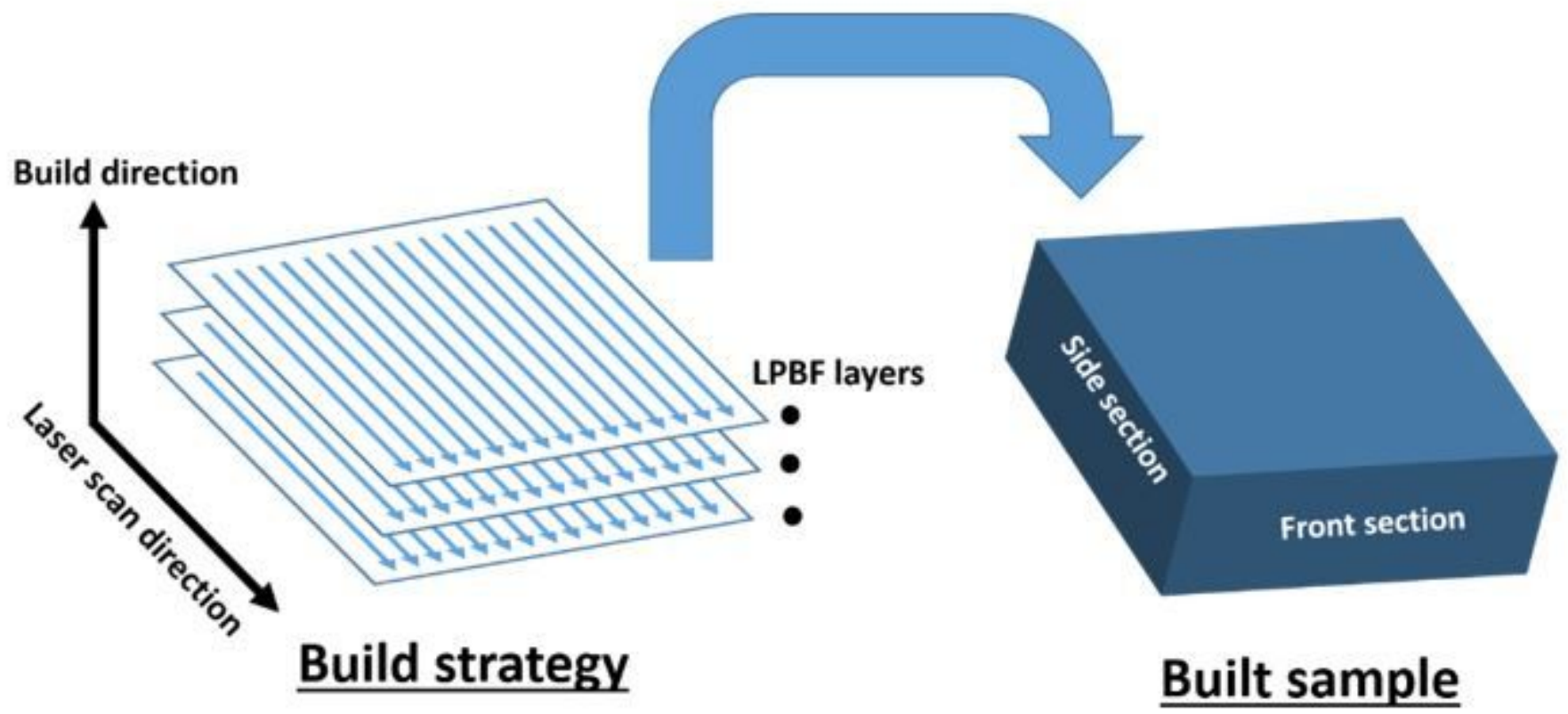

Figure 2

LPBF build strategy and the corresponding built sample with marked sections and directions for mechanical testing. 


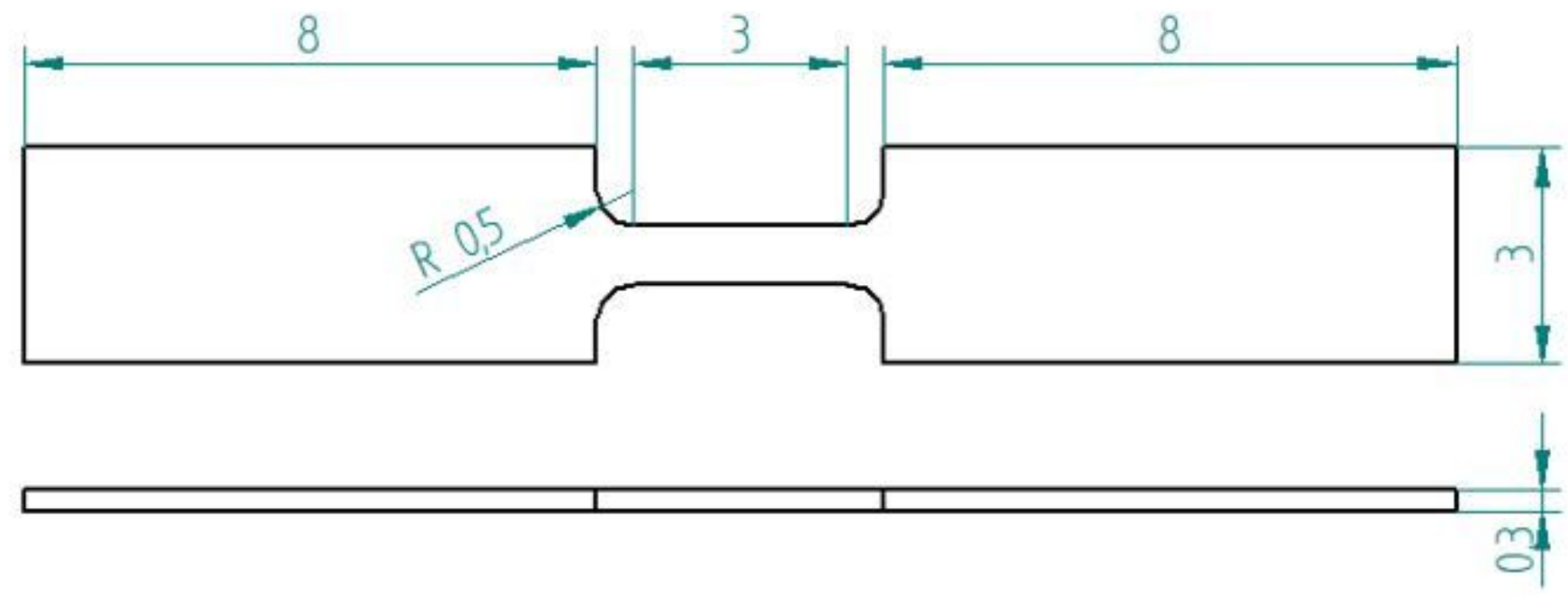

Figure 3

Dimensions of the micro-tensile test specimen

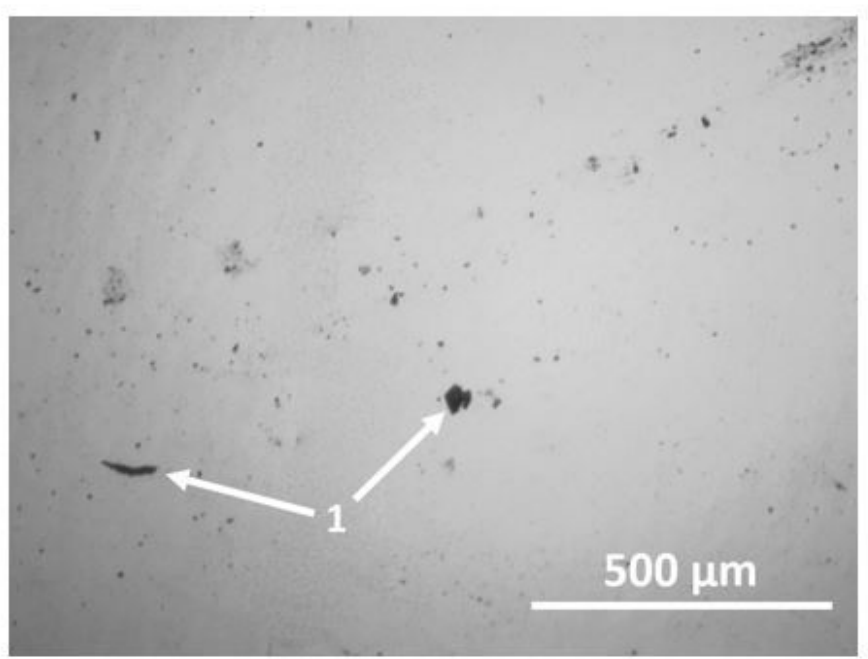

(a)

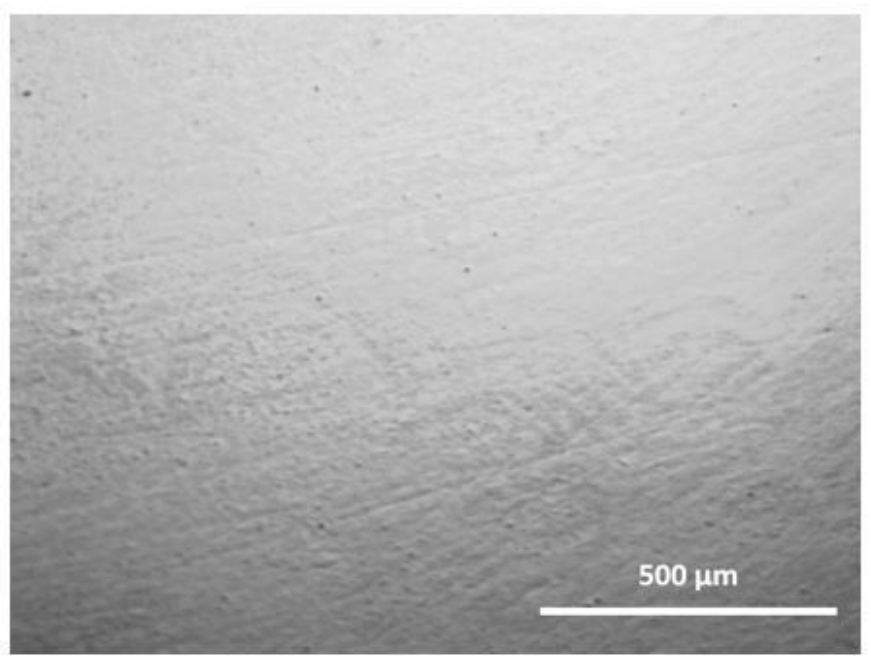

(b)

\section{Figure 4}

Typical cross-section images of (a) as-built samples showing irregular porosity,(b) HIP samples with reduced porosity. 


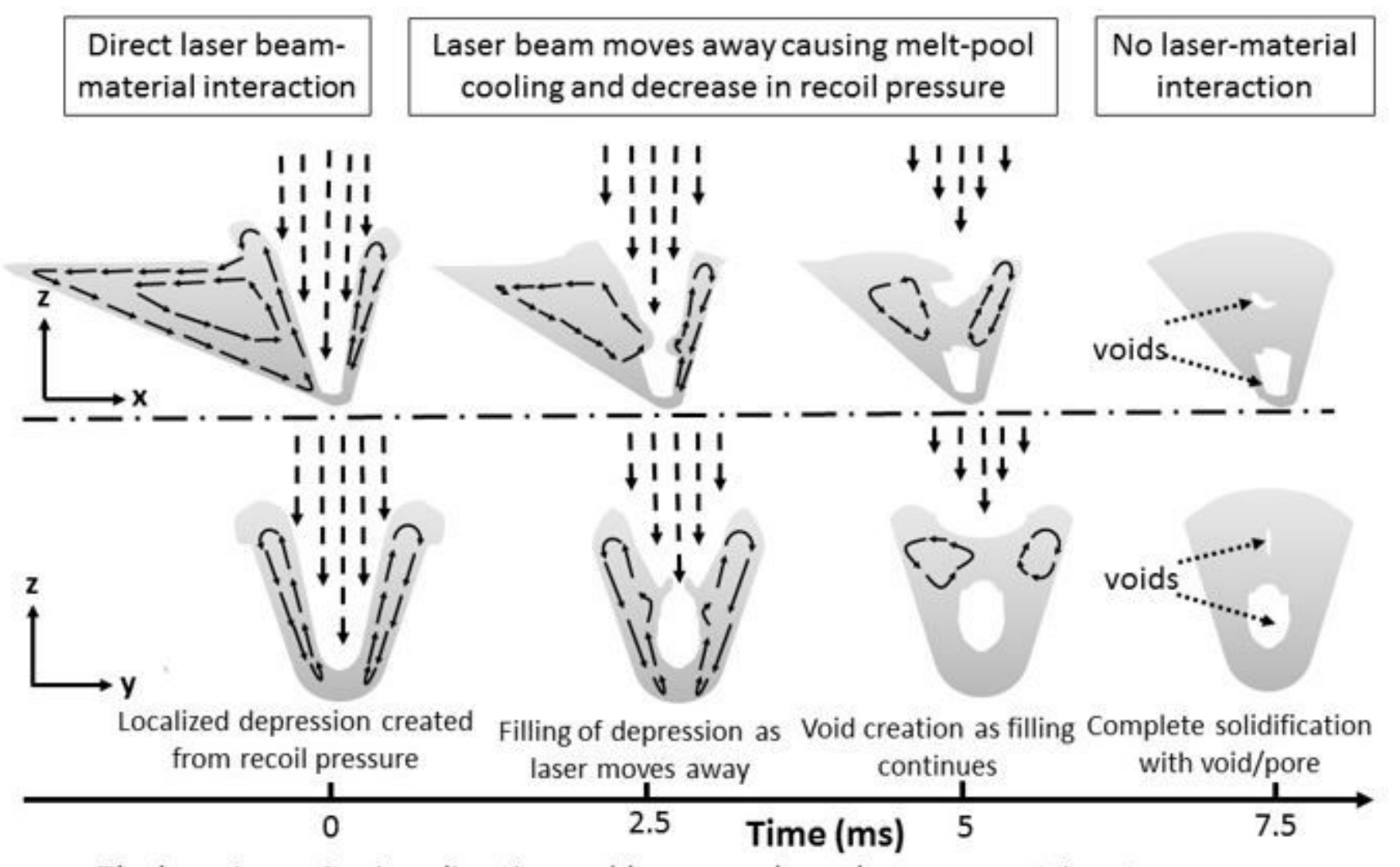

- The laser is moving in $x$-direction and hence $y z$-plane shows symmetric nature.

- The dashed arrows represent the direction and intensity of the force on the melt-pool generated from the recoil pressure.

- The solid arrows represent the melt-pool flow direction due to marangoni convection.

\section{Figure 5}

Void formation mechanism from recoil pressure effects during LPBF 


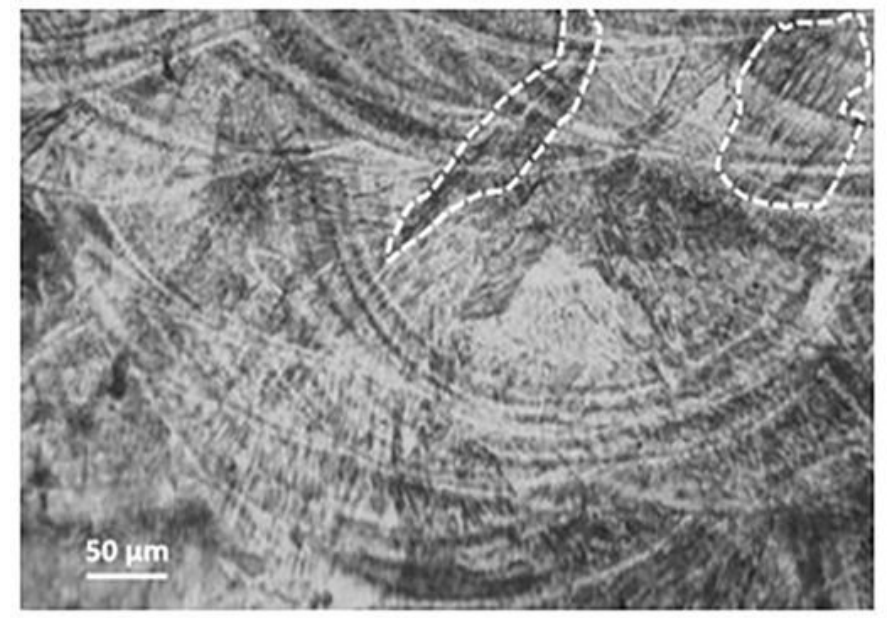

(a)

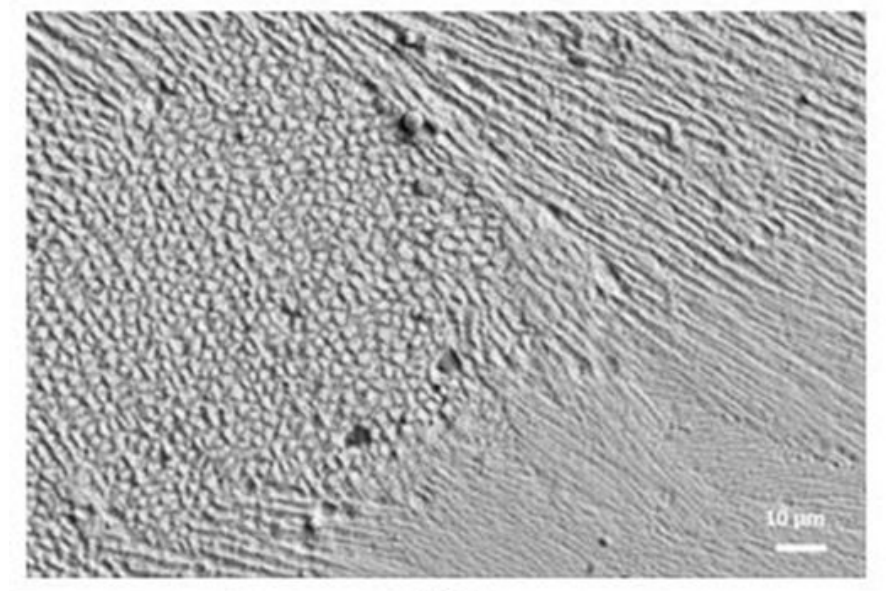

(b)

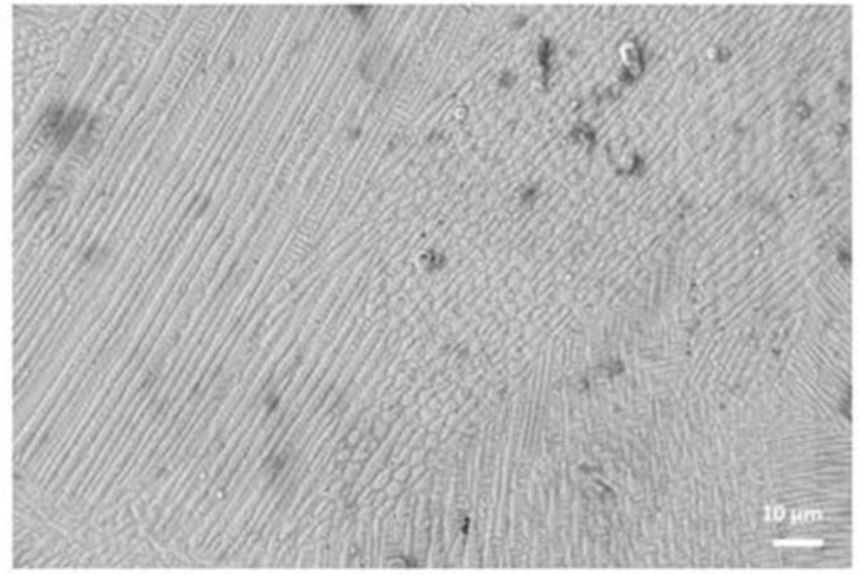

(c)

\section{Figure 6}

Microstructure of the (a) as-built sample showing melt-pool boundaries b) as-built sample at bottom layers (c) as-built sample at the top layer. 


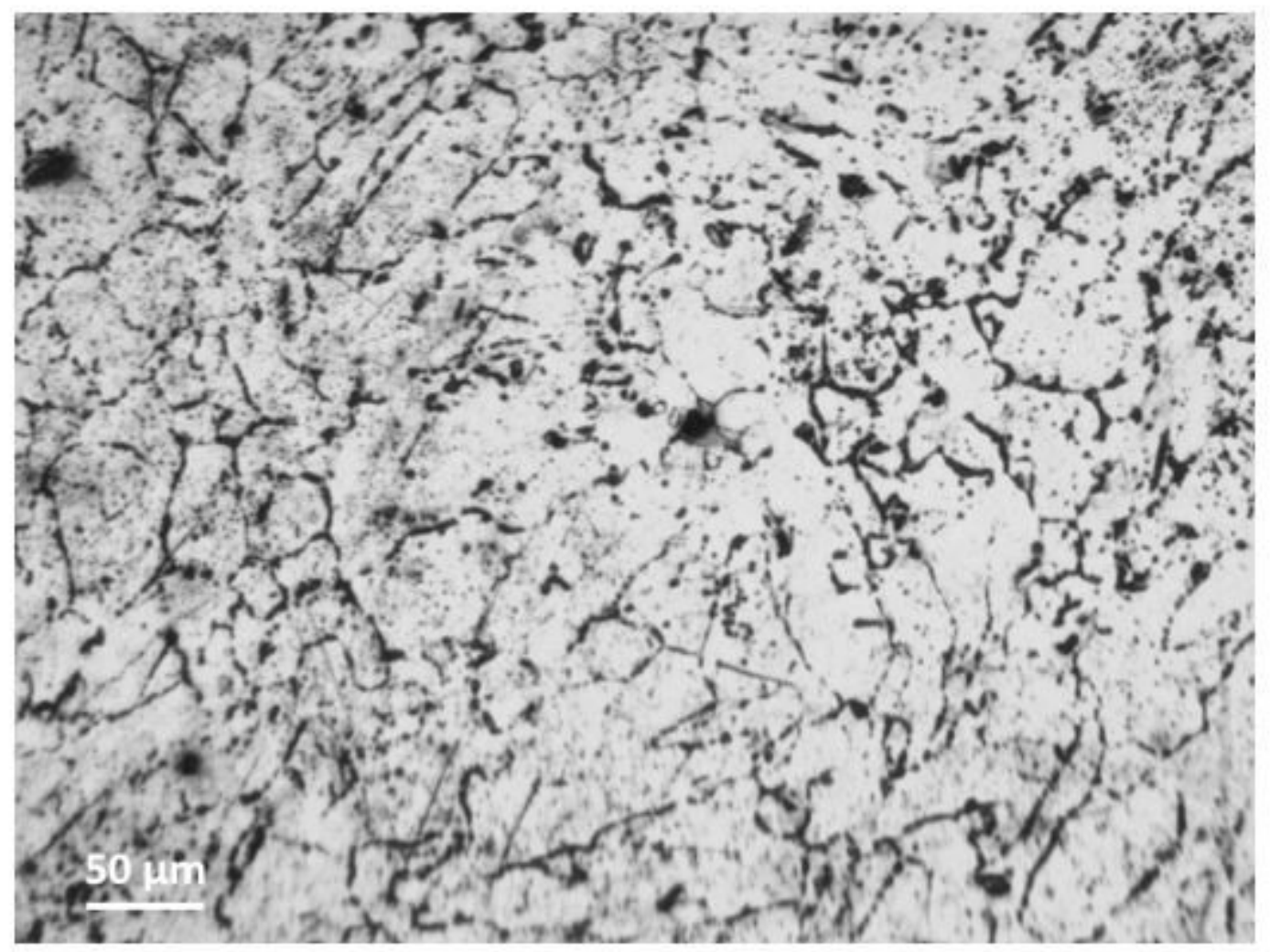

Figure 7

Microstructure of the LPBF built IN625 HIPed samples 
$\mathrm{Ni} \mathrm{Ka}$
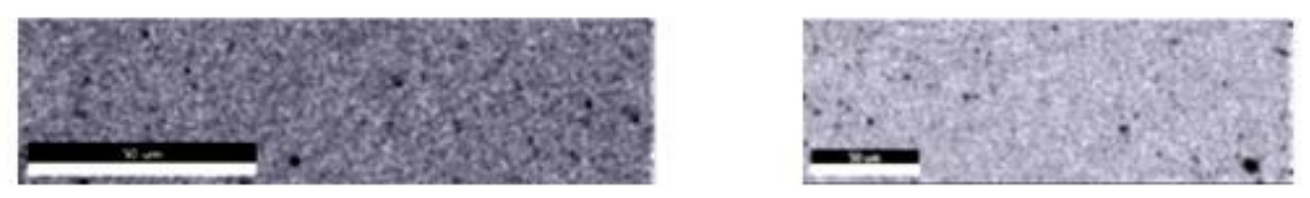

$\mathrm{Cr}_{\alpha}$
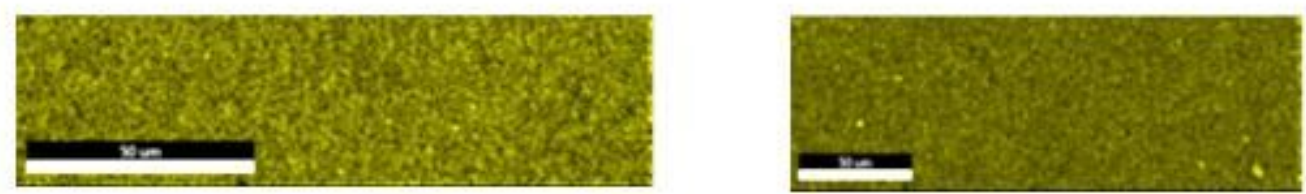

$\mathrm{C} \mathrm{K}_{\alpha}$
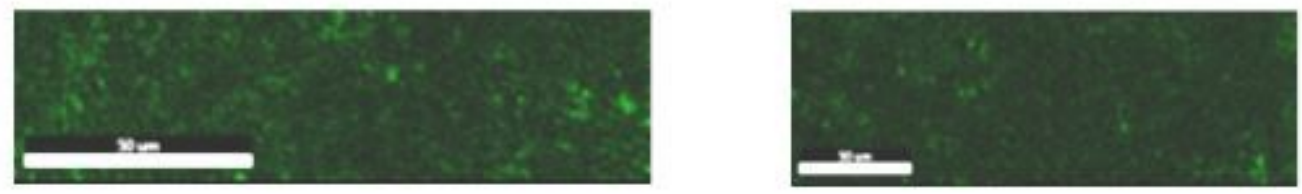

Mo $\mathrm{L}_{\alpha}$
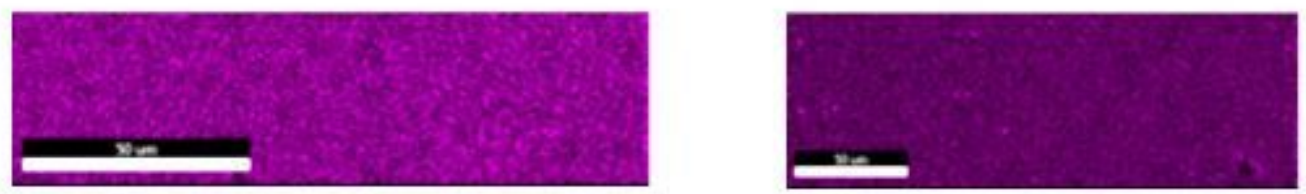

$\mathrm{Si} \mathrm{K}_{\alpha}$
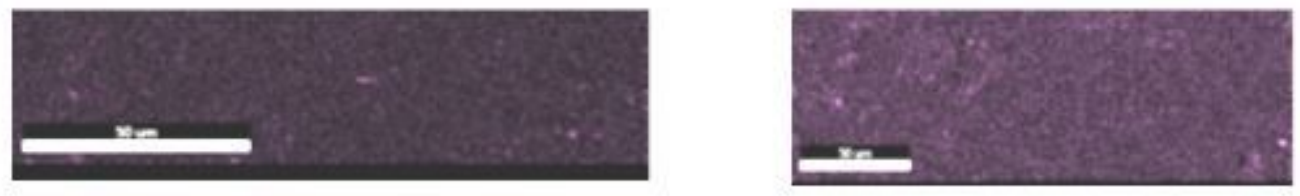

$\mathrm{Nb} \mathrm{L} \alpha$

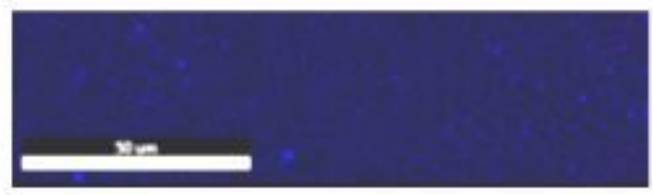

(a)

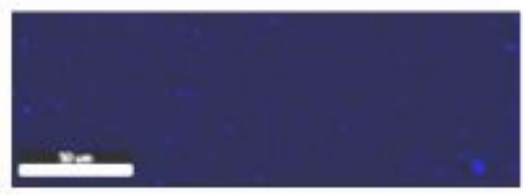

(b)

Figure 8

Elemental mapping of (a) as-built (b) HIPed samples of IN625 


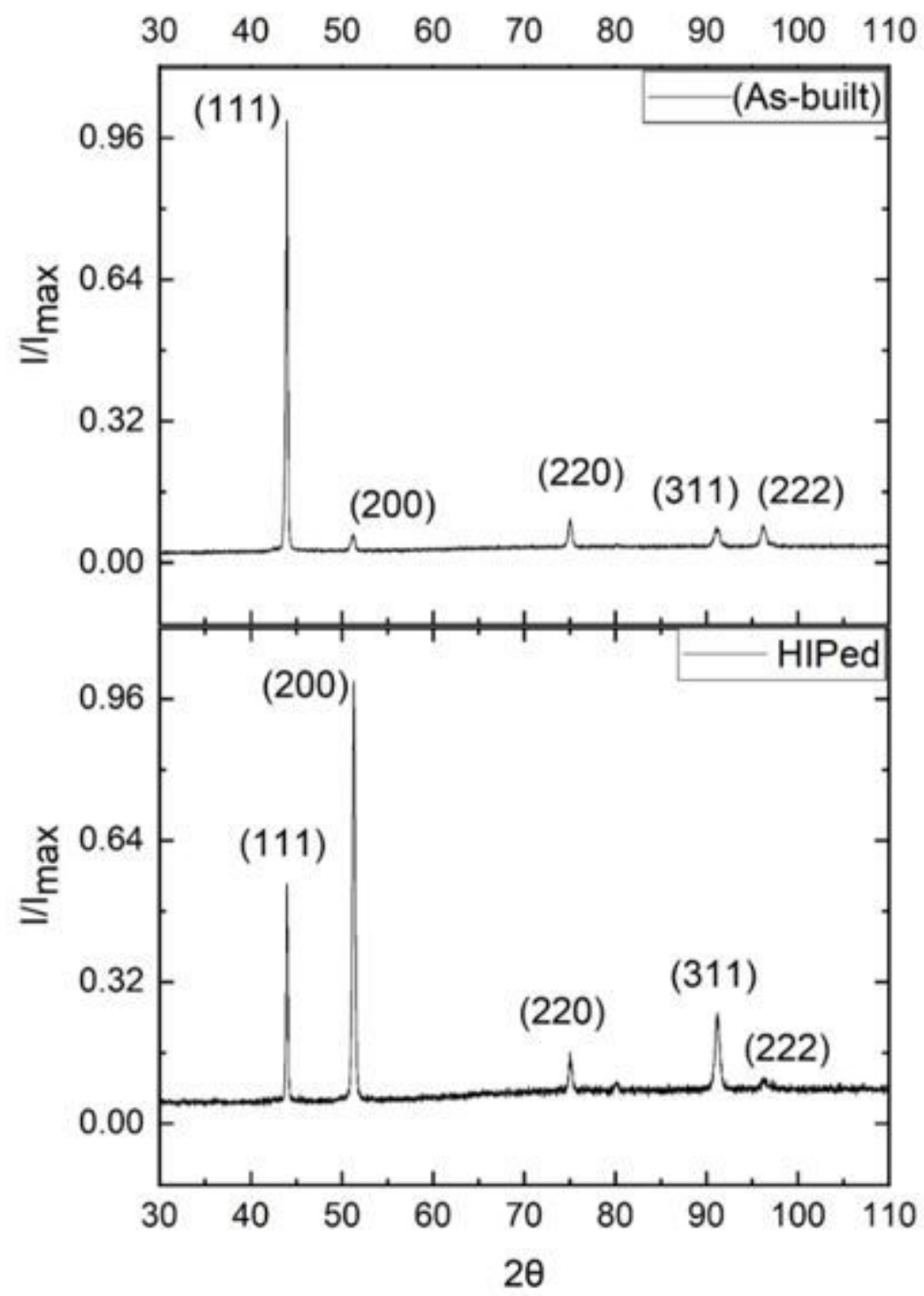

Figure 9

XRD plot obtained for as-built and HIPed IN625 samples 


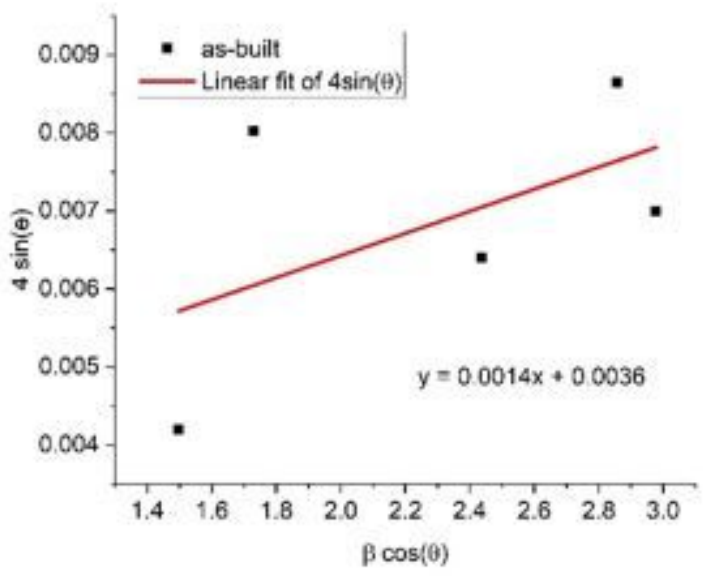

(a)

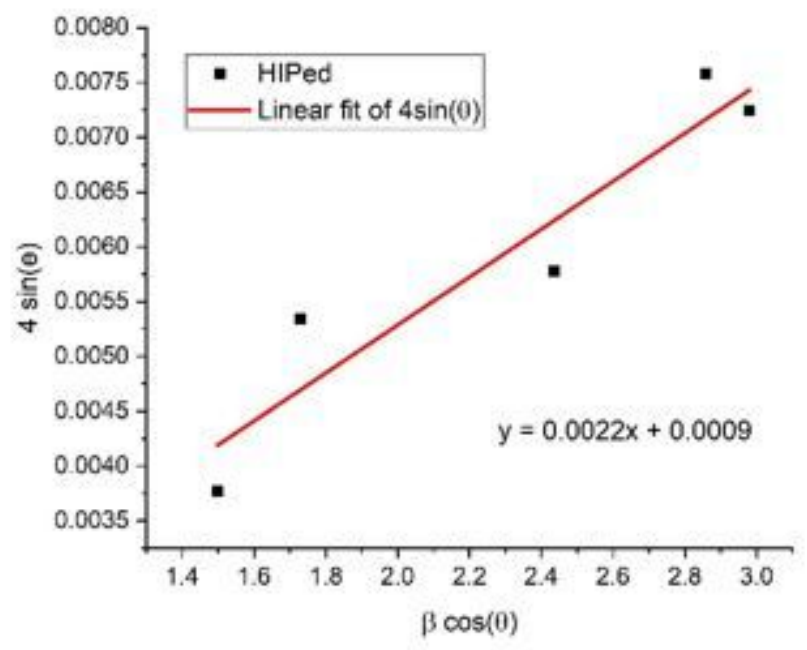

(b)

Figure 10

W-H plots in the (a) as-built condition and (b) HIPed condition. 


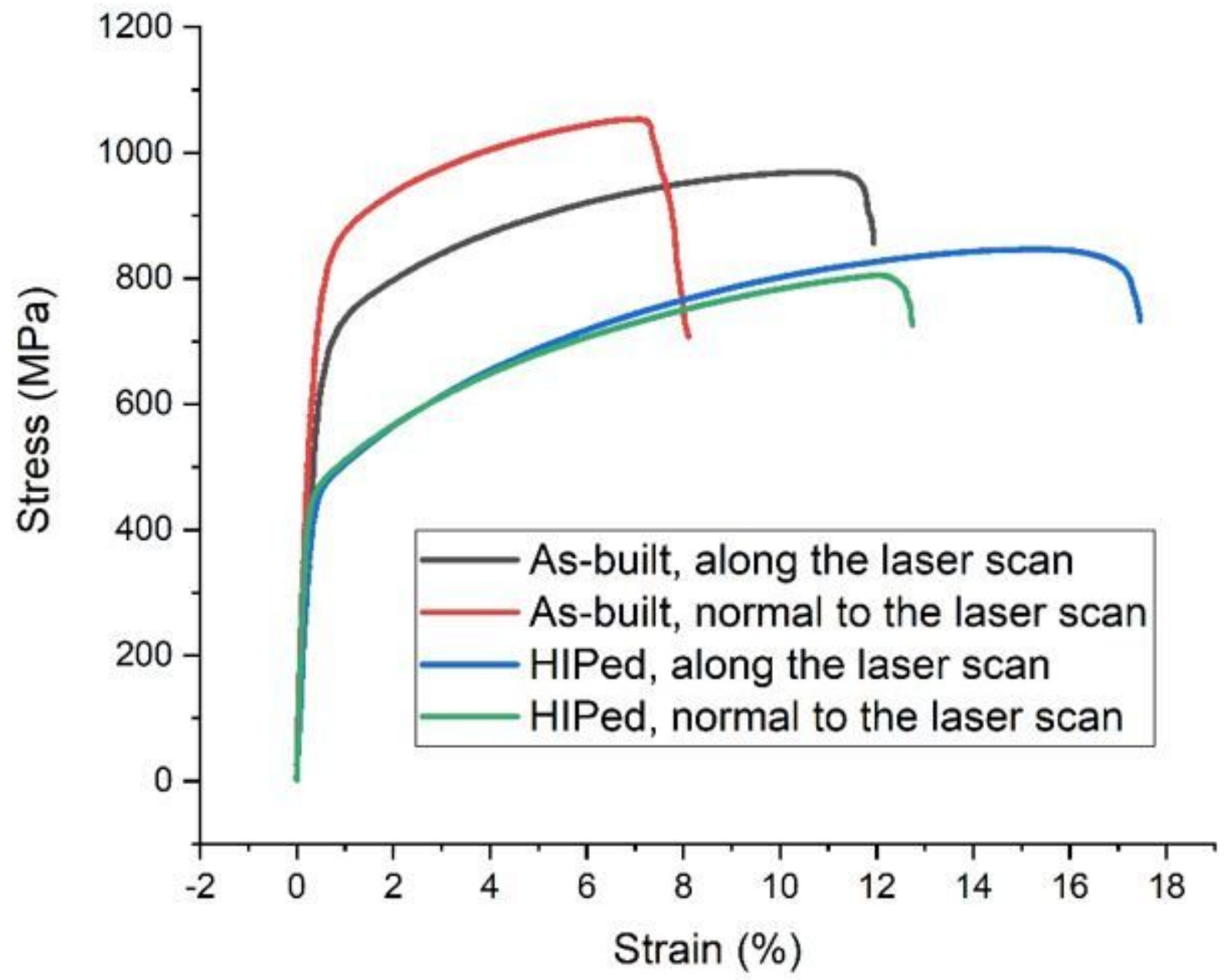

Figure 11

Stress-strain curves obtained for as-built and HIPed IN625 samples. 


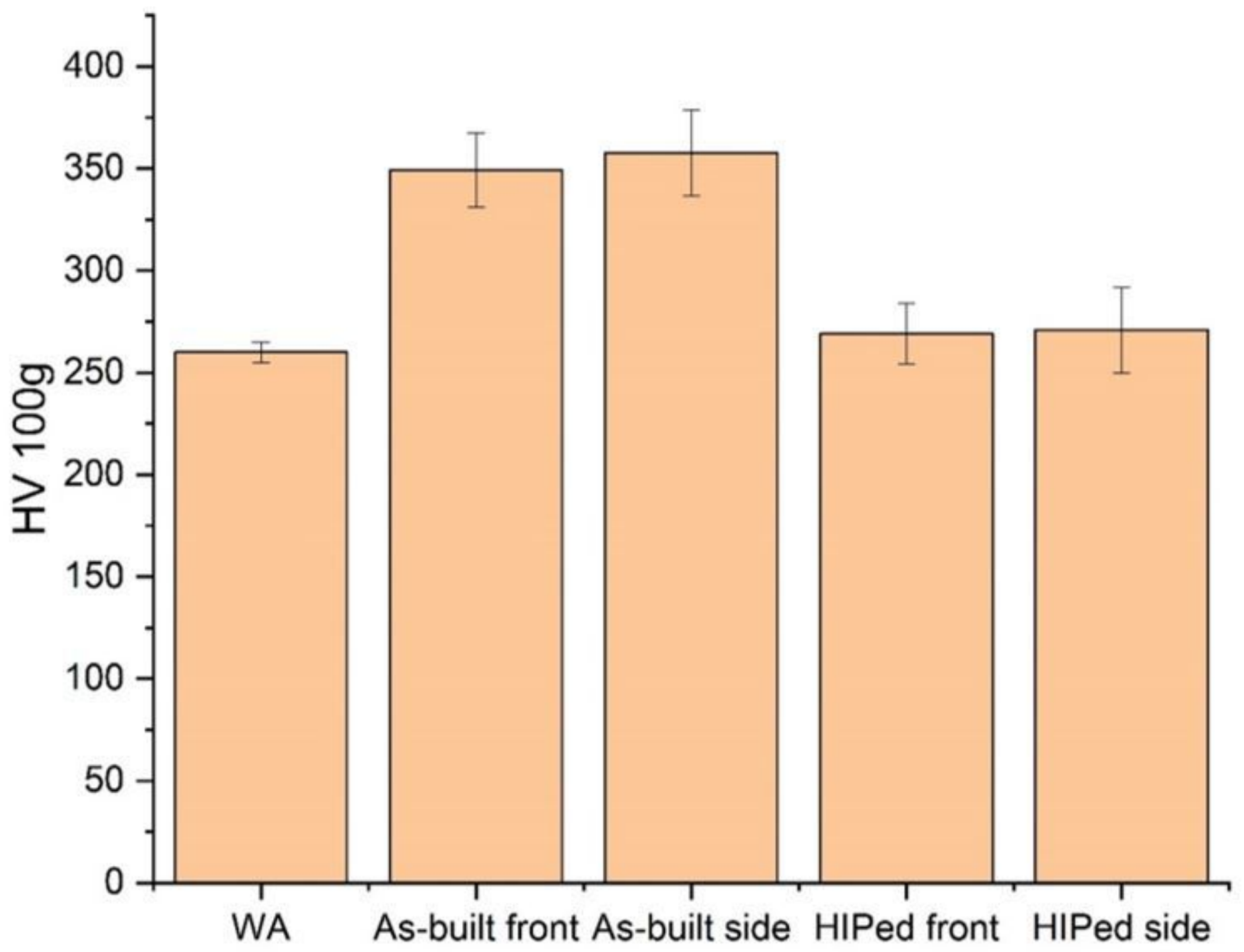

Figure 12

Micro-hardness of WA samples; as-built and HIPed samples on the front and the side sections 


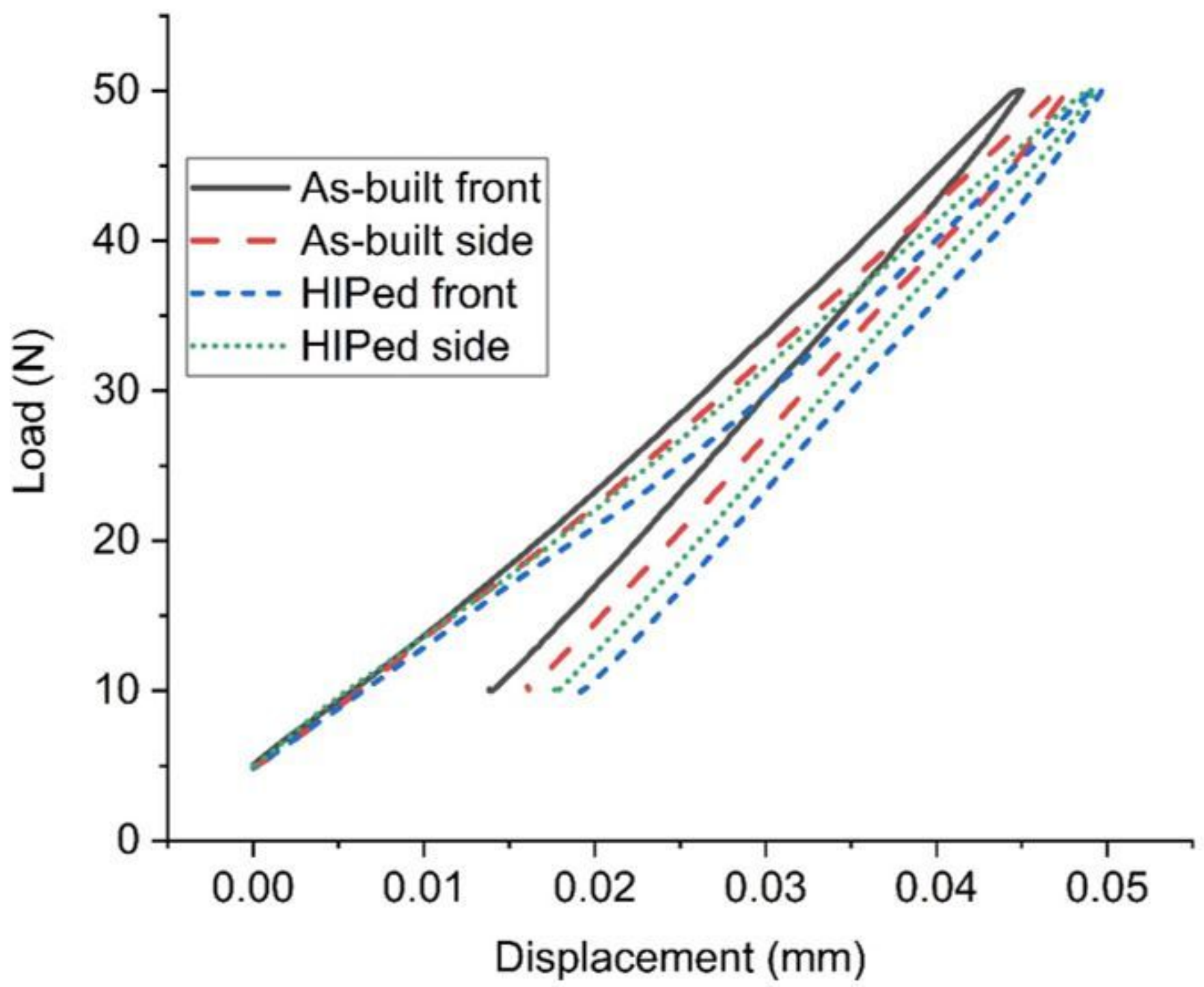

Figure 13

Load vs. displacement curve from single-cycle $A B I{ }^{\circledR}$ 